\title{
Maxillary etymologies
}

\author{
N. Cooper ${ }^{1}$ and L. Cascarini ${ }^{2}$
}

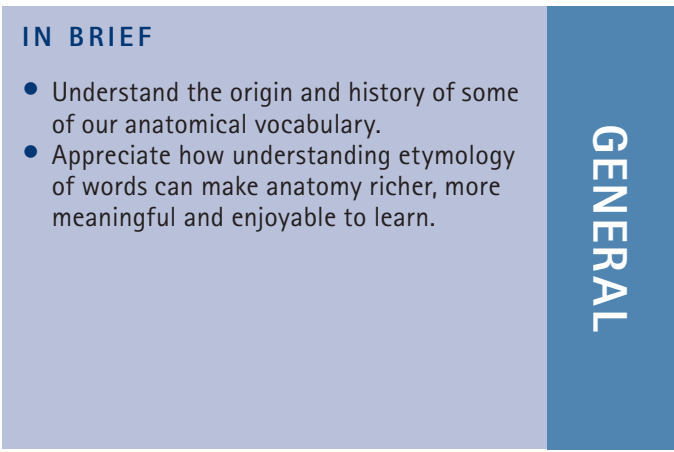

Our vocabulary grows as undergraduates, and continues to develop as we continue to grow as dental professionals. For many of us not learned in Latin or Greek, we are too busy learning what words mean rather than appreciating why a word means what it does. This article aims to clarify where words relating to the maxilla are derived from, why they are used and how they are related to other similar words in everyday use.

The jaws are the tooth bearing bones and consist of two maxillary bones which form the upper jaw, and the mandible which is the lower jaw. Early anatomists used the term maxilla for both mandible and maxilla, as Latin (L) maxilla means simply jaw bone. Later anatomists reserved maxilla for the upper jaw and used mandible, L mandere - to chew with for that which chews against it.

The two maxillary bones meet at the intermaxillary suture, L inter - between, and L sutura - a sewing or seam and support the teeth of the upper jaw. The term suture is important and is quite precise. Because the two maxillary bones are joined by a suture they remain two distinct bones, we have a left and a right maxilla. Conversely the mandible is formed by the fusion at the midline symphysis, forming a single bone because symphysis ( $\mathrm{Gr}$ growing together) is a fixed union. Therefore, strictly speaking, if a surgeon performs a total maxillectomy it would involve removal of half the upper jaw whilst a total mandibulectomy would remove the whole lower jaw,

*Dental Student (OMFS Trainee), Guy's, King's and St Thomas' Dental Institute, Kings College, London; ${ }^{2}$ Specialist Registrar, Oral and Maxillofacial Surgery, Kings College Hospital, Denmark Hill, London, SE5 9RS

*Correspondence to: Dr Nicholas Cooper

Email: nickcoops@hotmail.com

\section{Refereed Paper}

Accepted 16 June 2008

DOI: $10.1038 /$ sj.bdj.2008.844

${ }^{\oplus}$ British Dental Journal 2008; 205: 393-394 a bilateral maxillectomy would remove the whole upper jaw.

Each maxillary bone consists of a body and four processes:

- The palatine process from L palatum - palate (not relating to Palatine Hill in Rome, which is from $\mathrm{L}$ palatium - a palace). The term palate later became synonymous with taste, hence palatable, and is not related to palett which is from old French meaning small shovel blade

- The frontal process, frontal is from L frons - the forehead or brow (ie front of head), and was also used to mean countenance or expression, perhaps as the brow is so expressive. The genitive of $\mathrm{L}$ frons is frontis, which became the front of anything and hence frontier as a front or boundary

- The zygomatic process from Greek (Gr) zygon - a yoke applied because the shape of the zygomatic arch resembles the bar (yoke) to which the two animals where tied in order to pull a carriage or plough. From this 'yoke' also came to mean a bond or tie hence the term zygote came into being because the zygote is formed by fusion (yoking) of two gametes. The other term for zygomatic bone is malar from L malar - cheek bone and is probably related to L Malum - an apple, presumably because of the resemblance of red cheeks to a ripe apple
- The alveolar processes are derived from L alveolus - a small tray or basin and was also applied to a game in which pebbles were held in small depressions. By extension, alveolus came to mean any hollowed out structure.

In the midline the maxillary bones articulate with each other and anteriorly, in combination with the nasal bones form the piriform aperture. The piriform (anterior nasal) aperture is from L pirium - a pear and L forma - shape or form. This describes the pear-like shape of the piriform fossa, as seen in an anterior view of the skull (from Anglo Saxon skulle - $a$ bowl). It is not, as is commonly thought, from pyramidal. At the floor of the piriform aperture the anterior nasal spine is formed. You may wonder what a small spike and the backbone have in common. Spine is from L spina - a thorn or thorny bush. The backbone is therefore called spine because the vertebral protuberances resembles a thorny twig.

Passing through the aperture the maxillary bones articulate with the vomer which is so named because of its appearance, from L vomer - ploughshare (the large pointed blade of a plough which cuts a slice of earth). The septal cartilage is derived from L saeptum - dividing enclosure, fence or wall, and L cartilago - gristle. However, tumours of cartilage are not called cartilagomas but chondromas from the Gr chondros - cartilage. Also in 
the midline the maxillae articulate with the ethmoid bone, Gr ethmos - a sieve and eidos - resemblance, because of its many perforations particularly at the cribriform plate which rather predictably is from L cribrium - a sieve. Within the piriform aperture is a pair of small delicate bones, the inferior nasal conchae from $\mathrm{L}$ nasalis - relating to the nose and $\mathrm{L}$ nasus - nose. This can be confusing because Gr nosus means disease, so nosology is not the study of noses, but of diseases. Concha is from L concha - a seashell, classically of a bivalave. A conch shell features in Hindu tradition, used as a trumpet during worship, and appears in William Golding’s ‘Lord of The Flies'; it symbolises democracy and order.

Below each concha is a meatus, L meatus - motion, movement or channel because it is here that various cavities communicate with the nose, including the maxillary antrum from Gr antron - a cave.

The tiny lacrimal bone sits on the upper surface of each maxillary bone around the tear sac and is so named from L lachryma - a tear as in lachrymose which means given to weeping.

On the facial surface of the maxilla is the canine eminence, from $\mathrm{L}$ caninus - of the $d o g$ and L eminere - to project. Also on the facial surface is the infra orbital foramen, from L orbis - a ring or circle and L foramen - an opening and L forare - to bore

On the palatal surface of the maxillae in the midline is a shallow incisive fossa from L incidere - to cut into and L fossa - a ditch. Posteriorly each alveolus has a maxillary tuberosity from L tuber - $a$ knot or collection and -sity - condition.

Finally the buccinator is attached to the maxilla from L buccinator - a trumpeter which needs no explanation. 